Daimon. Revista Internacional de Filosofía, Suplemento $n^{\circ} 7$ (2018), pp. 139-149

ISSN: 1130-0507 (papel) y 1989-4651 (electrónico)

http://dx.doi.org/10.6018/daimon/333491

\title{
La fraternidad, condición de la justicia
}

\author{
Fraternity as a Condition of Justice*
}

VICTÒRIA CAMPS**

\begin{abstract}
Resumen: El artículo empieza con un recorrido por las ideas republicanas del 1848 francés en torno a la fraternidad como idea fundamental para combatir el individualismo e instaurar un nuevo orden social. No obstante, el ideal de fraternidad es rápidamente ignorado por el pensamiento político contemporáneo, contrariamente a o que ocurre con los dos otros dos términos de la divisa revolucionaria: la libertad y la igualdad. La autora se plantea si conviene recuperar el concepto de fraternidad y en qué sentido. ¿Es una virtud en el sentido aristotélico? Pese a que hay filósofos contrarios a esa idea, se defiende la tesis de que es difícil que sin fraternidad pueda hacerse justicia y que, en consecuencia, la fraternidad no puede ser vista sino como una virtud o una obligación moral imprescindible como base de la cooperación social.
\end{abstract}

Palabras clave: Fraternidad, Justicia, Socialismo, Virtud, Cooperación.

\begin{abstract}
The article starts with an overview of the idea of fraternity developed by the republican French thinkers around 1848. Fraternity was seen as the main idea to fight individualism and set up a new social order. But fraternity has been rapidly ignored by contemporary thought, contrary to what has happened to the two other mottos of French Revolution -liberty and equality. We are wondering now weather it is necessary to recover the concept of fraternity and in what sense it should be understood. Is it a virtue in the aristotelian sense of the word? It seems to the author the more understandable way to consider fraternity $-\mathrm{a}$ virtue or moral obligation essential for social cooperation or justice.
\end{abstract}

Keywords: Fraternity, Justice, Socialism, Virtue, Cooperation.

\section{La construcción de la fraternidad moderna}

Es una obviedad decir que la fraternidad no es un concepto moderno. Según sean los precedentes que queramos encontrarle, podemos remontar el origen del concepto a la filosofía griega y, en concreto, al papel que ocupa en ella la amistad. Me refiero tanto a la amistad aristotélica, virtud fundamental de la ética y de la política, como a la amistad epicúrea que es el sustento de la comunidad de filósofos del célebre jardín donde se discutían las

Recibido: 02/06/2018. Aceptado: 02/07/2018.

* Este artículo se ha elaborado gracias al proyecto de investigación financiado por el Ministerio de Economía y Competitividad FFI-2015-64858-P.

** Universitat Autònoma de Barcelona. Catedrática Emérita. victoriacamps@gmail.com. Autora del libro reciente La fragilidad de una ética liberal (Bellaterra, El espejo y la lámpara, 2018). 
doctrinas de una de las escuelas helenistas más atractivas. En cualquiera de los dos casos, la amistad es restrictiva: une a los iguales, en la acepción de Aristóteles, o a los seducidos por la forma de vida que predica Epicuro. Sólo cabe retener del concepto la necesidad de un vínculo que una a los individuos, ajeno a las normas y más espontáneo que ellas, sin el cual es imposible construir una vida común. Más allá de esa reminiscencia, el pasado más evidente de la fraternidad moderna y revolucionaria es la fraternidad cristiana que deriva del mandamiento del amor. En este caso, el vínculo quiere hermanar, en principio, a todos los cristianos y, por extensión, a todo los hombres y mujeres, en su calidad de hijos de Dios. Es ahí donde la metáfora funciona mejor: el cristianismo puede hablar de hermanos en la fe gracias a la filiación divina, una hermandad que sólo es real para el creyente y que, al mismo tiempo, obliga, puesto que las metáforas dan imágenes de una realidad que está lejos de reflejarlas sin equívocos. Hablamos de un término a la vez descriptivo y normativo. El "ama al prójimo como a ti mismo" es un imperativo que, a diferencia de otros imperativos éticos no amparados por la religión, se refuerza en la esperanza. En efecto, la fraternidad o la igualdad de todos los hombres ante Dios, que en el mundo terrenal dejan mucho que desear, en el reino de los cierlos serán una realidad.

Algo de la reminiscencia cristiana se mantiene en el ideal de fraternidad de la célebre tríada de la revolución francesa. Especialmente cuando la apelación a la fraternidad se convierte en uno de los reclamos del republicanismo francés de 1848. Conceptos como el de asociación y cooperación son ideas clave con vistas a abordar los problemas de carácter político, económico y social en el seno de la lucha de clases, como se desprende del siguiente texto: "Desde los pastores de la Iglesia a los representantes de la economía burguesa, todas las bocas hablan de asociación como de un hecho mágico y maravilloso, una suerte de 'ábrete sésamo' que debía realizar la edad de oro de la fraternidad universal" (Gaumont, 1924, t.I, p. 238). Efectivamente, para los republicanos franceses, asociaciación y cooperación son sinónimos de fraternidad, y suponen una nueva estructuración de las actividades económicas, una alternativa a la forma de organización liberal. "Si se nos preguntara cual es vuestra ciencia, responderemos: ¡La Fraternidad! ¿Cuál es vuestro principio? ¡La Fraternidad! ¿Cuál es vuestra doctrina? ¡La Fraternidad! ¿Cuál es vuestro sistema? ¡La Fraternidad!” (Le Populaire, 4/11/1844).

Frente a la exaltación del individuo y las libertades individuales, propia del pensamiento liberal, la asociación es un principio que conlleva la solidaridad entre los hombres y que da cuenta de que la fraternidad es un valor que une a las personas. Justifica que existan obligaciones recíprocas entre los individuos y de la sociedad hacia ellos. El principio de asociación pone a los problemas colectivos por delante de los individuales, es vista como la condición necesaria para construir una sociedad armónica, fraternal, solidaria, sin antagonismos derivados del individualismo. Es la manera de acabar con el espíritu egoísta e individualista.

A su vez, con la idea de asociación se buscaba sustituir la dispersión de esfuerzos individuales por el fomento de la cooperación. Tal era la idea matriz del socialismo como alternativa al dominio del capital sobre la clase obrera: "El socialismo era, para los trabajadores más ilustrados, la supresión del predominio atribuido al capital, y una alianza entre los trabajadores para la producción industrial, alianza fundada en el principio de fraternidad: era el trabajo ejecutado en común para el beneficio común" (Audiganne, 1845, p. 208). De esta forma, se trataba de introducir una doctrina humanitaria de conciliación, a partir de la 
convicción de que el individuo no es un átomo aislado que sólo existe en tanto que miembro de una comunidad. Convicción que, sin embargo, debía hacerse compatible con la creencia en la libertad que era el principio de las teorías políticas de Rousseau y Kant. La fraternidad y la solidaridad como disposiciones del individuo a tener en cuenta al otro preservaban la libertad sin dejar por ello de propiciar la acción comunitaria en beneficio de todos.

Este socialismo que se estructura y se expande en la segunda mitad del siglo XIX tiene un marcado carácter religioso, lo cual no es contradictorio con el anticlericalismo de la mayoría de quienes lo propugnan y defienden. A diferencia del socialismo alemán, el francés no deja de lado sus raíces religiosas y le cuesta entender el socialismo separado del mensaje cristiano. En realidad, a propósito del sentido religioso de la fraternidad republicana, lo que menos cuenta es la fe en un ser trascendente, y lo que más, la doctrina moral del cristianismo. La moral cristiana es considerada necesaria como guía de la acción política porque señala una vía de regeneración y salvación que se contrapone a la concepción del individuo aislado. El adalid de dicho movimiento es Luois Blanc que, en su Cathécisme socialiste, se expresa sin equívocos: “¿Qué es el socialismo? Es el Evangelio en acción [...] El socialismo tiene como meta realizar entre los hombres estas cuatro máximas fundamentales del Evangelio: 1) amaos los unos a los otros; 2) no hagas a los demás lo que no quieras que te hagan a ti; 3) el primero de entre vosotros debe ser el servidor de los demás; y 4) ipaz a los hombres de buena voluntad!" (Blanc, 1849, p. 39).

Con la mente dirigida a la divisa revolucionaria -Liberté, egalité, fraternité-, Blanc no predicaba la lucha de clases, sino más bien la armonía entre todos los hombres y las clases sociales. A diferencia del principio de autoridad y del individualismo, los dos principios que habían dirigido la historia hasta el momento, la opción por la fraternidad era percibida como el principio de una organización social capaz de resolver los mayores conflictos. Efectivamente, las sociedades gobernadas por el principio de autoridad aceptaban ciegamente la existencia de desigualdades y estaban fácilmente dispuestas a justificar la coacción y someterse a las tradiciones. Por su parte, el principio individualista sitúa al individuo al margen de la sociedad, lo enfrenta a ella al otorgarle un sentimiento exaltado de sus derechos individuales sin hablarle de sus deberes. La fraternidad, por el contrario, "considerando solidarios a los miembros de la gran familia, tiende a organizar un día las sociedades, obra del hombre, basándose en el modelo del cuerpo humano, obra de Dios, y basa el poder del gobierno en la persuasión, en el consentimiento voluntario de los corazones" (Blanc, 1847-1862, pp. 9-10).

A juicio de Blanc, abrazar el ideal de fraternidad implica una serie de reivindicaciones y críticas al individualismo imperante, que se concretan en los que deberían ser los hitos fundamentales de un nuevo orden económico y social. Son los siguientes ${ }^{1}$ :

a) El sufragio universal cuyo reconocimiento significa la primera medida en la adopción del principio de fraternidad y el fin del período marcado por el individualismo. A juicio de Blanc, la Revolución de 1789 estuvo marcada, en primer término, por el carácter individualista propio de pensadores ilustrados como Voltaire. Ahora debía imponerse la doctrina de Rousseau, una nueva revolución en nombre de la fraternidad como condición de las libertades individuales.

1 En lo que sigue, me baso en el estudio de Jesús González Amuchastegui, 1989. 
b) La paz social, que no es otra cosa que la efectiva reconciliación de los intereses individuales y colectivos, derivada de la convicción de que en ninguna sociedad existen individuos que sólo sean individuos. La instauración de un régimen fraternal debía consistir en el fin de la lucha de todos contra todos y de la libre competencia: "Pidiendo justicia para los pobres, velamos por el rico, al que un golpe de suerte puede precipitar en la pobreza. Pidiendo protección para los débiles, pensamos también en vosotros, poderosos de la actualidad, pues el viento de las vicisitudes humanas puede de un momento a otro despojaros de vuestra fuerza. Sí, todos los hombres son hermanos; sí, todos los intereses son solidarios" (Blanc, 1839, p. 14). En la comunidad fraternal, todos velan por todos, no hay intereses privativos de un sector porque los intereses "verdaderos" son los de todos los ciudadanos.

c) El principio de asociación debe sustituir al individualismo. Sólo a partir de él se concibe correctamente la república que no consiste sólo en la alternativa a la monarquía, ni siquiera en la proclamación del sufragio universal. Mientras se fomente el egoísmo y los individuos se conciban como seres aislados o, lo que es peor, antagónicos, no se conseguirá la unidad social, política y moral. En el orden económico, el principio de asociación se concreta en las cooperativas, como alternativa al régimen salarial.

d) Libertad, igualdad y fraternidad son valores complementarios. La libertad formal intensamente criticada por Marx no hace a los proletarios "libres de hecho", que es lo que se trata de conseguir. Para ello, hay que proporcionarles algo más que libertad, a saber, instrumentos de desarrollo y de trabajo. Sin la igualdad y la fraternidad, buscaremos en vano la libertad que será sólo un engaño.

Así pues, el principio de fraternidad, a ojos de Blanc, consiste en una nueva forma de concebir la sociedad, como una gran familia. Un valor, en opinión de Blanc, anterior a la justicia porque no procede del hombre sino de Dios. La proximidad del concepto al clima existente en las comunidades cristianas, donde todos sus miembros se sienten hermanos, es evidente. La comunidad así entendida no sólo obliga a cada uno de sus miembros a ayudar a los más necesitados, sino que, sobre esa base, son conciliables la libertad del individuo y la pertenencia del mismo a la colectividad. No lo son, en cambio, en un sistema donde lo que rige es la libre competencia. En definitiva, lo que el principio de fraternidad pretende poner de manifiesto es la necesidad de reconciliar la perspectiva individual y la colectiva desde la convicción de que sólo si se adoptan ambas perspectivas podrá abordarse eficazmente el funcionamiento de la comunidad política ${ }^{2}$.

\section{La fraternidad como virtud}

Sin el encumbramiento de la fraternidad por el éxito de la divisa revolucionaria francesa, que ha dado nombre desde entonces a los valores de la modernidad, y sin el posterior

2 No se le oculta a Blanc que lo que se sigue en la práctica del principio de fraternidad es irrealizable sin una intervención efectiva del estado que debería ser "el regulador supremo de la producción", procurando la existencia de talleres sociales y cooperativas, controlando la igualdad de salarios, así como atendiendo a las necesidades básicas de los trabajadores con fondos de asistencia social y aliviando a la industria en épocas de crisis. Cf. González Amuchastegui, 1989, pp. 301 ss. 
desarrollo del concepto por republicanos como Louis Blanc, es posible que el ideal de una humanidad fraternal hubiera caído inmediatamente en el olvido o se hubiera conservado, en todo caso, como una reminiscencia de la doctrina cristiana. De hecho, como noté en mi libro Virtudes públicas (Camps, 1990, pp. 33 sigs.), de los tres valores revolucionarios, el de la fraternidad ha sido el que ha tenido una vida más corta. Rápidamente fue ignorado por la filosofía y por la política, debido sin duda a sus connotaciones religiosas y, sobre todo, a la dificultad de convertirlo en un principio normativo. Se puede legislar sobre la libertad y sobre la igualdad, pero no sobre la fraternidad. Ésta, o bien se les supone a los humanos como un derivado lógico de concebirse como miembros de una misma especie, o bien se descarta como una metáfora bella pero imposible e incluso inútil para corregir las desigualdades y las injusticias que se ciernen inexorables sobre la mayoría de seres humanos.

Por otro lado, fraternidad viene de frater, "hermano", un término poco compatible con las reivindicaciones feministas que pronto vieron en él una prueba más de la dominación masculina sobre las mujeres. Es cierto que, como acabamos de ver, la idea de hermandad entre los humanos estaba presente en los idearios socialistas del siglo XIX y que, en muchos casos, era concomitante al ideal de luchar por sociedades más igualitarias, en las que todos y cada uno de los individuos pudieran gozar de una libertad real y no sólo formal, pero fue la igualdad como derecho la idea que se impuso políticamente, en tanto que la fraternidad debió verse como un concepto innecesario y superfluo. En todo caso, la noción fue pronto sustituida por otra, la de solidaridad, que carecía de connotaciones religiosas y machistas y parecía más apropiada para llenar el vacío que no cubría el principio de igualdad.

La pregunta que nos planteamos hoy al propósito es si conviene o no recuperar la idea de fraternidad y, en caso afirmativo, qué sentido habría que darle. Es un hecho, y las críticas más incisivas al pensamiento liberal se han ocupado de señalarlo, que en las sociedades liberales se echa de menos algo que consiga agregar voluntades, cohesionar a las personas y comprometerlas en torno a proyectos comunes. Dicho de otra forma, en tales sociedades es difícil construir ciudadanía. Los individuos de las democracias liberales se han acostumbrado a vivir atomizados, a las grandes sociedades les falta la calidez de la comunidad. Y ello ha ocurrido después de que se haya dado un impulso decisivo al ideal de igualdad, tras la Declaración Universal de Derechos Humanos de 1948 y el papel que en ella tienen, por primera vez, los derechos sociales. No sólo nos encontramos hoy en unas condiciones que han puesto de manifiesto que los logros conseguidos por el estado de bienestar parecen tener fecha de caducidad, sino que los conflictos y las guerras no han cesado. Nada permite esperar que estemos evolucionando hacia sociedades más fraternales, con un sentido de pertenencia a una humanidad común, del que puedan derivarse logros notables.

En Virtudes públicas concluía que la solidaridad -no la fraternidad que la consideré obsoleta- era una de las virtudes que sin ninguna duda requerían las democracias de nuestro tiempo. La solidaridad, decía allí, tenía dos funciones en nuestros estados sociales de derecho: 1) impulsar medidas de equidad y, por lo tanto, promover políticas redistributivas más justas; 2) complementar los fallos de la justicia distributiva, proporcionando alivio y ayuda allí donde las medidas de equidad no llegan. En las sociedades laicas de los siglos XX y XXI, el cristianismo -mejor, el cristianismo más progresista- había visto claro que su misión fundamental estaba en el terreno de la solidaridad y, por lo tanto, en sus contenidos morales. Muchas organizaciones religiosas se habían ido convirtiendo en ONGs potentes. Además, 
la segunda mitad del siglo XX es testigo de la aparición de muchas formas de movimientos sociales impulsados así mismo por un compromiso de solidaridad. Dicha tendencia ha crecido en los últimos años. La crisis que empezó en 2008 no ha hecho sino reforzar entre nosotros la importancia y el valor de las movilizaciones solidarias, poniendo de relieve que éstas pueden llegar a ser más eficaces que la acción política.

Desde tal perspectiva, podríamos concluir que el intento de recuperar la fraternidad es un intento estéril. ¿Qué puede decirnos la fraternidad que no lo diga ya el concepto de solidaridad? Si a la solidaridad la calificamos sin problemas como una virtud en el sentido aristotélico del término, una cualidad que debería formar parte del carácter de la persona, ¿cabe decir lo mismo de la fraternidad?

Una de las pensadoras que, desde la filosofía, ha estudiado con más detalle y profundidad la cuestión de cómo debemos "pensar la fraternidad" en nuestro tiempo es Véronique Munoz-Dardé, quien se propone explicar el carácter político del concepto, la única forma de entenderlo, a su juicio, desde los atributos que hoy le convienen: una "fraternidad ciudadana, laica o republicana". En diálogo, sobre todo, con John Rawls, quien menciona escasamente el concepto pero, sin embargo, lo considera una exigencia necesaria para lo que él denomina "la estructura básica de la sociedad" (luego lo veremos con más detalle), Munoz-Dardé trata de corregir la intuición de que la fraternidad es pre-política, como algo que "se situa a priori, en el terreno de las actitudes del espíritu, de las convenciones, de las formas de conducta, o de comportamientos movidos por el sentimiento" (MunozDardé, 1994, p. 85). Esa es, en efecto, la manera habitual de entender el concepto, como un valor que no llega a ser político, porque, como puso de manifiesto Jules Michelet, "si la fraternidad se escribe en imperativo, deja de ser fraternal" (Ozouf, 1988, p.738). Pero a Munoz-Dardé no le satisface esa identificación de la fraternidad con un sentimiento. Tampoco quiere verla como el medio o el fin que se necesita para constituir una comunidad de valores, sino como "la expresión de un problema, que provisionalmente definiré como el de la tensión entre el punto de vista impersonal -el que define las instituciones equitativas como aquellas que se apoyan en el igual valor de todas las hermanas y hermanos- y el punto de vista personal de cada uno de los hermanos y hermanas sobre lo que consideran que es el sentido de su vida, primero, para ellos mismos, y después, para los demás. Definida así, la noción de fraternidad pondrá el acento más nítidamente sobre los elementos conflictuales y de tensión que sobre el consenso y la solidaridad grupal, de la que se distinguirá conceptualmente" (ibid., pp. 113-114).

Con esta precisión, la autora focaliza uno de los problemas fundamentales de las sociedades liberales: la dificultad de conciliar, en cada persona, la perspectiva personal y la impersonal. Inspirándose en Nagel, piensa que es la coexistencia de ambas perspectivas la que da lugar a los principios éticos que nacen de la confluencia de lo universalizable y lo particular. El problema en cuestión está cerca, y así lo reconoce la autora, de la dificultad de lograr un "pluralismo razonable", en la acepción de Rawls. Es, además, el meollo de la filosofía política moderna: cómo hacer compatibles la libertad y la igualdad, el individuo y la sociedad. Sólo una sociedad fraternal ofrece a los grupos y a los individuos "las mejores armas para gestionar la paradoja en sí mismos entre los dos puntos de vista morales, el personal y el impersonal" (ibid., pp. 125). 
A mi juicio, la perspicacia de Munoz-Dardé se encuentra en poner de relieve que es cada individuo quien debe conseguir la síntesis de lo personal y lo impersonal ya que sin ese logro la lucha por la justicia sólo encuentra obstáculos, los obstáculos derivados de los intereses personales de cada individuo o grupo. Ahora bien, si la conjunción de lo universal y lo particular ha de ser un logro personal, algo que vendría a caracterizar el compromiso que deben adquirir los ciudadanos en las democracias actuales, y algo que se ve como imprescindible a la luz de los conflictos y tensiones sociales, ¿por qué no entender la fraternidad como una virtud, en el sentido aristotélico de "una disposición adquirida voluntaria"? Munoz-Dardé rechaza explícitamente la concepción de la "fraternidad-crítica", así como la de la "fraternidad-virtud" porque, dice, en este último caso, no es algo que deba formar parte de la "naturaleza política del hombre". Es decir, comparte, en este punto, el rechazo de Rawls a un "humanismo cívico" de raíz aristotélica. No acabo de ver por qué. Tampoco lo veo justificado en Rawls. Si lo que refleja la necesidad de fraternidad es la dificultad de conseguir la síntesis de lo universal y lo particular, si conseguir la coexistencia en uno mismo del punto de vista parcial e imparcial es un deber moral, porque sin esa condición la moralidad personal no se sabe qué es ni en qué consiste, ¿no se deduce de ahí que ese esfuerzo - esa manera de ser, esa actitud- debe formar parte de la condición moral y política del ser humano? ¿Y si es así, no estamos hablando de una virtud? Es un hecho que la fraternidad entre los humanos es inexistente, pero la ética nos dice que sería bueno que existiera. ¿No es pensarla, en tal caso, como una virtud que debe ser adquirida, una "obligación moral" imprescindible para proteger a la sociedad de los excesos de individualismo y egoísmo?

Tampoco John Rawls parece entender la fraternidad como una virtud, sino más bien como un principio necesario en su teoría de la justicia, pero menos político que la libertad y la igualdad (Rawls, 1971, pp. 105 ss.). Por eso piensa que no ha tenido desarrollo en la teoría democrática. Rawls se pregunta por el lugar de la fraternidad en su propia teoría, y lo encuentra en el principio de la diferencia, pues considera que el rechazo a aceptar unas ventajas mayores en la redistribución de los bienes primarios, a menos que éstas repercutan en beneficio de los más desfavorecidos, responde al significado natural de la fraternidad. Si lo entiendo bien, Rawls viene a decir que sin la idea de fraternidad quizá no se explicaría esa tendencia de los individuos de una sociedad bien ordenada a admitir desigualdades sólo con la condición de que los más desfavorecidos se beneficien de ellas. ¿Pero de dónde sale dicha tendencia, que no es tan obvia? ¿Es tan inherente a la condición humana como lo es, por ejemplo, la compasión y que sólo precisa ser redirigida adecuadamente? ¿Es un valor que se adquiere en las sociedades que luchan por adecuar sus instituciones a los principios de la justicia? ¿Es un valor imprescindible para adquirir el sentido de la justicia? ¿O ambas cosas a la vez? Y, en el caso de constatar el fallo o la falta de ese valor, ¿qué se puede hacer para promoverlo?

\section{La justicia y la vida buena}

Las preguntas anteriores me llevan a considerar la distinción que establece Rawls entre las obligaciones de justicia y el concepto de vida buena. Una distinción que tal vez sirva para fines heurísticos, pero que, como tantas abstracciones filosóficas, choca con una práctica que se resiste a reproducir el rigor de los conceptos filosóficos. 
Uno de los aciertos de la teoría de la justicia rawlsiana, a mi juicio, es el dejar claro que el sujeto de la justicia son las instituciones políticas. A los tres poderes del estado -legislativo, ejecutivo y judicial- compete aplicar los principios de justicia, porque sólo ellos tienen capacidad y potestad para hacerlo. Los individuos, en todo caso, podemos ser solidarios y suplir las deficiencias de las instituciones públicas. Allí donde no llega la justicia, pueden llegar la caridad o la beneficencia. Ahora bien, no cabe duda de que los contenidos de la justicia -o los contenidos de lo que Rawls denomina "bienes primarios"han ido ampliándose y enriqueciéndose a lo largo de los años. Basta ir a la Constitución de los Estados Unidos para darse cuenta de cómo las distintas enmiendas agregadas a lo largo de los años han ido sustanciando unos derechos que, en un principio, dejaban mucho que desear. El sufragio de las mujeres, la abolición de la esclavitud, el reconocimiento de los derechos civiles no tuvieron capacidad normativa hasta que fueron incorporados a la Constitución. Antes de ello, la práctica de la esclavitud o la discriminación sexual o racial eran aceptadas como opciones de lo que hoy denominamos "vida buena", opciones de individuos que libremente escogían unas formas de vivir dentro del marco de lo legalmente permitido. Parece ser, pues, que los criterios de justicia no pueden deslindarse de unas determinadas concepciones de vida buena. A medida que éstas van descartando ciertas prácticas como injustas y discriminatorias, dichas prácticas o estilos de vida dejan de ser aceptables desde un punto de vista normativo y la sociedad en su conjunto es instada a rechazarlas. Se convierten en normas de justicia.

Si esto es así, entre la vida buena y la justicia se da una relación de continuidad que hace difícil verlas como ámbitos separados y distintos. Es cierto que uno es libre de elegir la religión que quiera, sí, pero sólo en la medida en que su doctrina no interfiera y, por supuesto, no dañe, la vida de los demás. Las dificultades que tenemos para condenar ciertas formas abusivas de la libertad de expresión dan cuenta de que las fronteras entre la justicia y el bien no son claras. Dicho de otra forma, aunque en una sociedad liberal, el individuo ha de gozar de libertad para construir su vida a su antojo, esa libertad no sólo tiene los límites establecidos por la ley, sino otros límites menos precisos, que no siempre pueden fijarse normativamente, pero cuya ausencia o ignorancia pone en cuestión que la vida que uno se propone construir pueda ser denominada "buena". Como dijeron hace años los filósofos analíticos, lo bueno es una cualidad indefinible, lo que no significa que no sepamos qué es. O, por lo menos, no es tan difícil señalar aquellas formas de vida que claramente no son buenas, pese a que quizá cumplan los requisitos impuestos por la legalidad vigente. Muchas de las consecuencias de la globalización financiera, como las políticas fiscales proclives al fomento de la acumulación de la riqueza, la fuga de capitales fuera de los países de residencia de las élites económicas y la falta de compromiso de éstas con los problemas de sus sociedades, todo ello, aun cuando pueda justificarse desde los marcos legilativos vigentes, ha derivado en pautas de comportamiento que dudaríamos en calificar como componentes de una "vida buena". Es "buena" para las élites, no cabe duda, pero no lo es si las palabras "ética" o "moral" siguen teniendo un significado mínimamente unívoco.

El libro de Robert \& Edward Skidelsky, How Much Is Enough? expone con agudeza el problema que intento plantear. Ambos autores parten de la teoría de la justicia de John Rawls, pero discrepan precisamente en la tesis de que los requerimientos de la justicia 
puedan separarse de determinadas concepciones del bien. Para hacerlo, echan mano del concepto de fraternidad, como se desprende de la siguiente cita con la que concluye el libro: "La igualdad se funda en la fraternidad, y no al revés. De ahí se sigue que no puede haber una respuesta abstracta, a priori, como la que intenta Rawls a la pregunta: ¿¿Cuánta desigualdad es excesiva?"'(Skidelsky, 2012, p. 160).

Tienen razón. La misma que no le falta a Jürgen Habermas, cuando se cuestiona la posibilidad de construir una Europa más democrática si no se consigue que los Estados dejen de mirar hacia sí mismos y sus intereses y se muestren más solidarios. En una conferencia pronunciada en abril de 2013, con el título "Democracia, solidaridad y la crisis europea", Habermas desarrollaba la idea de que la solidaridad es un acto político, a diferencia de las obligaciones morales que nacen de lazos comunitarios, como las que vinculan a los miembros de una familia. Dichos lazos son vínculos de la Sittlichkeit, que también se dan en las relaciones de solidaridad, con la diferencia de que éstas no se sustentan en relaciones prepolíticas, como las familiares, sino en asociaciones políticas o intereses políticos. En suma: "Las conductas basadas en la solidaridad presuponen contextos políticos, es decir, artificiales" (Habermas, 2013).

Habermas identifica la solidaridad con la fraternidad. Asume que la base de la fraternidad es religiosa, pues todas las religiones aluden a una comunidad de creyentes por encima de las comunidades locales. Piensa que, en la primera mitad del siglo XIX, la idea de fraternidad se fusionó con la de solidaridad, en el contexto de la lucha de clases, donde adquirieron sentido las llamadas a la solidaridad por parte de los movimientos obreros para combatir las relaciones competitivas del mercado. Esas relaciones regulan los intercambios mercantiles, pero son insuficientes como regla de las relaciones humanas. "Lo que se requiere, en cambio, es solidaridad, un esfuerzo cooperativo, a partir de una perspectiva política compartida, para promover el crecimiento y la competitividad en la zona euro como conjunto" (ibid.).

Estamos en un círculo, uno de los círculos característicos del razonamiento filosófico. En las sociedades democráticas es preciso que las instituciones funcionen bien y cumplan con su cometido de atender al bienestar colectivo. Al mismo tiempo, necesitamos una ciudadanía dispuesta a cooperar con los principios de la justicia y a construir sus vidas (buenas) desde tal perspectiva. Pero eso no ocurre. No porque carezcamos de las instituciones y de los principios de justicia adecuados, no porque desconozcamos o hayamos dejado de suscribir los derechos fundamentales, sino porque no se dan los vínculos de fraternidad o solidaridad entre las personas, vínculos imprescindibles para que los ideales de justicia no sean un puro engaño. El círculo es este: la fraternidad es una condición para la justicia, pero no parece florecer allí donde están vigentes y teóricamente se acatan los principios de justicia. La pregunta que atormenta a Rawls sigue en pie: ¿cómo es posible la cooperación social? Es la misma pregunta para la que Kant no halló una respuesta convincente: ¿cómo es posible que la razón moral obligue? En términos más concretos, podemos evocar las palabras de Oran Pamuk en una entrevista reciente: "Si existe la fraternité, hacer que cierta gente se deje la vida en pequeños barcos está en las antípodas. La política antiinmigratoria y la derecha casi racista están acabando con los valores de Europa”.

Valores reconocidos, sin duda, pero que nunca han dejado de ser algo más que meros valores teóricos, esto es, para decirlo con Sartre, palabras que nombran algo que no existe. 


\section{Las estructuras de la fraternidad}

Escribía Enrique Gil Calvo, en un artículo reciente, que el eslogan de la revolución burguesa: "libertad, igualdad, fraternidad" había sido sustituido por este otro: "libertad, igualdad, competitividad", pues "la fraternidad ha quedado arrumbada en nombre de la competitividad neoliberal" (Gil Calvo, 2014). Efectivamente, las estructuras económicas de ese capitalismo que el socialismo decimonónico combatió con prédicas de fraternidad y armonía, siguen en pie. Lejos de aminorar las desigualdades, las políticas a favor de los derechos humanos y de la justicia no han conseguido sostener el movimiento iniciado tras la Segunda Guerra Mundial a favor de una garantía real de los derechos sociales. El célebre libro de Thomas Piketty, El capitalismo del siglo XXI, ha revelado con datos indiscutibles que las desigualdades han crecido más que nunca en los últimos treinta años. Es decir, en lugar de conseguir desmantelar las estructuras capitalistas lo que se está desmantelando es el estado social.

La reflexión hecha hasta aquí a propósito de la función que el principio de fraternidad puede tener en nuestro mundo me lleva a dos conclusiones no muy alejadas de las que ya vislumbré en Virtudes públicas: 1) Está claro que las sociedades que aspiran a ser más libres e iguales no conseguirán sus objetivos si sus ciudadanos no son capaces de cultivar la fraternidad o la solidaridad (no consigo poder diferenciar un concepto del otro en cuanto a sus aplicaciones prácticas); 2) Esto es así porque si es cierto que sin igualdad no hay libertad real, también lo es que sin fraternidad no se avanza hacia una mayor igualdad. No se avanza porque ni los ciudadanos exigen a sus gobiernos medidas más equitativas, ni están dispuestos a compensar las muchas injusticias que el sistema económico va produciendo.

¿Quiere esto decir que la fraternidad ha de ser entendida como un principio político o como una virtud? Mi conclusión es que ambas maneras de caracterizarla no son incompatibles. La fraternidad es una virtud (o un deber moral) que debe ser cultivada por todos y cada uno de los ciudadanos que se enorgullezcan de serlo. Una virtud adquirida a través de la educación y a través de un ethos social y cultural que la reconozca como algo valioso. El problema no está tanto en la educación, sino en la no existencia de ese ethos. Porque la construcción de un determinado ethos no depende sólo de la buena voluntad de los individuos, que nunca será generalizada, sino de cambios estructurales en la sociedad que promuevan otro tipo de valores que los económicos. Creo que es ahí donde se sitúa la necesidad de entender la fraternidad no sólo como virtud, sino como un principio político. Un principio que, efectivamente, no puede ser normativo en el sentido en que lo es una ley tributaria que obliga a redistribuir las rentas, pero que es político en la medida en que contribuye a modificar estructuras que obstaculizan el cultivo de la fraternidad o no le otorgan el valor que merece. Precisamente, a raíz de la crisis económica, se está viendo con mayor claridad que sin cambios estructurales de calado no sólo no se podrá sostener el estado de bienestar, sino que no se conseguirán reducir los vicios de un sistema que, como todo el mundo está de acuerdo en reconocer, sólo genera más desigualdades.

Si la fraternidad tiene que convertirse en un vínculo que armonice de verdad a las personas, se necesitan asociaciones y movimientos que la promuevan. Hace falta introducir el sentido de la cooperación en el seno de las organizaciones económicas, como, por ejemplo, propugna La economía del bien común de Christian Felber. Es una flagrante contradicción 
-explica Felber- que los valores que rigen en la estructura familiar y en muchas estructuras sociales no tengan un parangón en las organizaciones económicas o en las organizaciones políticas. Los movimientos sociales surgidos desde la crisis económica, los nuevos partidos políticos nacidos con la intención de regenerar el ethos democrático y mantener la autenticidad de los compromisos sociales, pueden ser un buen punto de partida de esos cambios estructurales a favor de una fraternidad más real.

\section{Bibliografía}

Audiganne (1845), Les populations ouvrières et les industries de la France dans le mouvement social du XIXème siècle, París.

Blanc, L. (1839), “Suite a l'introduction”, Révue du Progrès, 1 de junio de 1839, t.I.

Blanc, L. (1847-1862), Histoire de la Révolution Française, París, Langlois et Leclerq.

Blanc, L. (1849), Catéchisme des socialistes, París, Au Bureau du Nouveau Monde.

Camps, V. (1990), Virtudes públicas, Madrid, Espasa Calpe.

Felber, Ch. (2012), La economía del bien común, Deusto Ediciones.

Gaumont, J. (1924), Histoire générale de la cooperation en France. Les idées et les faits. Les homes et les oeuvres, 2 tomos, París, Féderation Nationale des Cooperatives de Consommation.

Gil Calvo, E. (2014), "La hegemonía de la competitividad”, La Maleta de Portbou, Barcelon, $\mathrm{n}^{\circ} 4$.

González Amuchastegui, J. (1989), Louis Blanc y los orígenes del socialismo democrático, Madrid, Centro de Investigaciones Sociológicas.

Habermas, J. (2013), "Democracy, Solidarity and the European Crisis", Leuven, 26 April 2013.

Munoz-Dardé, V. (1994), La Fraternité: un concept polique? Essai sur une notion de justice politique et sociale, Tesis doctoral.

Nagel, Th. (1991), Equality and Partiality, Oxford , Oxford University Press.

Ozouf, M. (1988), "Fraternité”, en Dictionnaire critique de la Révolution Française, Furet et Ozouf (eds.), Paris , Flammarion, pp. 731-741.

Piketty, T. (2014), El capital en el siglo XXI, Madrid, Fondo de Cultura Económica, 2014.

Rawls, J. (1971), A Theory of Justice, Oxford University Press.

Skidelsky, R. \& E. (2012), How Much Is Enough? Money and the Good Life, New York, Other Press. 
